\title{
Naringin inhibits ovarian tumor growth by promoting apoptosis: An in vivo study
}

\author{
LIPING CAI ${ }^{1}$, HELI WU ${ }^{2}$, CHUNHUA TU ${ }^{1}$, XIAOCHUN WEN ${ }^{2}$ and BEI ZHOU ${ }^{2}$ \\ ${ }^{1}$ Department of Obstetrics and Gynecology, The First Affiliated Hospital of Nanchang University; \\ ${ }^{2}$ Graduate School, Nanchang University, Nanchang, Jiangxi 330006, P.R. China
}

Received July 5, 2017; Accepted November 16, 2017

DOI: $10.3892 / \mathrm{ol} .2018 .8611$

\begin{abstract}
The aim of the present study was to investigate the antitumor activities of naringin in ovarian cancer, and to assess the underlying mechanisms. Ovarian tumor cells were implanted into nude mice to produce ovarian tumors in vivo. The mice were divided into six groups: Control, low dose naringin $[0.5 \mathrm{mg} / \mathrm{kg}$, intraperitoneal (i.p.)], middle dose naringin $(1 \mathrm{mg} / \mathrm{kg}$, i.p.), high dose naringin $(2 \mathrm{mg} / \mathrm{kg}$, i.p.), positive control (cisplatin, $2 \mathrm{mg} / \mathrm{kg}$, i.p.) and a combination of cisplatin and naringin (both $2 \mathrm{mg} / \mathrm{kg}$ ). Following administration of naringin and/or cisplatin, the tumor size and weight were measured. Apoptosis of tumor cells was detected using a terminal deoxynucleotidyl transferase dUTP nick end labeling assay. Apoptosis-associated gene expression was detected using reverse transcription-polymerase chain reaction and immunohistochemistry. In the range of $0.5-2 \mathrm{mg} / \mathrm{kg}$, naringin dose-dependently inhibited tumor growth, as demonstrated by a decrease in tumor size and weight. Naringin promoted apoptosis of the ovarian tumor cells. Additionally, naringin reduced the expression of B-cell lymphoma (Bcl)-2, Bcl-extra large (Bcl-xL), cyclin D1, c-Myc and survivin, while it increased the expression of caspase-3 and caspase-7. The data demonstrated that naringin inhibited ovarian tumor growth in vivo. Its mechanisms may be associated with caspase-7-, caspase-3-, Bcl-2- and Bcl-xL-mediated apoptosis. Nevertheless, the clinical application of naringin in the treatment of ovarian cancer requires further study.
\end{abstract}

\section{Introduction}

Ovarian cancer is a common type of malignancy, and also the main cause of gynecological cancer mortality (1). Due to the location of the ovaries, there are no notable symptoms in the early stage of carcinogenesis (2). The majority of patients are

Correspondence to: Dr Liping Cai, Department of Obstetrics and Gynecology, The First Affiliated Hospital of Nanchang University, 17 Yong Wai Zheng Street, Nanchang, Jiangxi 330006, P.R. China E-mail: cailip11@163.com

Key words: naringin, ovarian cancer, apoptosis, cyclin D1 diagnosed with advanced-stage ovarian cancer, with the symptoms including an abdominal mass, ascites and notable weight loss (3). Surgery combined with chemotherapy is still the most effective treatment for ovarian cancer (4). Surgery has the ability to eliminate the tumor foci, but it is difficult to completely remove the tumor with surgery alone (5). Furthermore, ovarian cancer cells are prone to metastasize, and the numerous small tumor metastases are problematic due to the difficulty in observing them without a microscope (6). Therefore, chemotherapy is required following surgery to suppress residual tumors, though the frequent use of chemotherapeutic agents can cause adverse reactions and drug resistance (7).

Chinese herbal medicines are extensively reported to kill tumor cells, as well as to not be susceptible to drug resistance and to have few adverse effects (8). Naringin is a bioflavonoid and polyphenolic compound that is located in grapefruit (9). Previous studies have indicated that naringin has a number of pharmacological activities, including anti-inflammation, anti-oxidative stress, myocardial protection, and the regulation of glucose and lipid metabolism (10). Naringin can also induce cancer cell apoptosis via eliminating free radicals using its antioxidant activity, and by inhibiting oncogene expression and cell proliferation (11-13). Naringin can inhibit carcinogenic substance-induced DNA chain destruction, which maintains the stability of genetic information and prevents the occurrence of DNA mutations (10). Additionally, naringin effectively inhibits $\beta$-carotene, which in turn reduces carcinogenic substance-induced DNA chain destruction $(14,15)$; however, the antitumor effect of naringin in ovarian cancer and its underlying mechanism remains unknown.

Xenotransplanted cells are vital for investigating the mechanisms underlying tumorigenesis and treatments (16). In the present study, an in vivo tumor model was established via implanting SKOV3 cells in nude mice, and the intervention of naringin was evaluated by calculating the size and weight of tumors. Furthermore, apoptosis was detected in order to investigate the role of naringin in the treatment of ovarian cancer. The current study aimed to provide preclinical evidence for the treatment of ovarian cancer with naringin.

\section{Materials and methods}

Cell culture. The SKOV3 cell line was purchased from The Shanghai Institutes for Biological Sciences, Chinese Academy 
of Science (Shanghai, China). The cells were cultured at $37^{\circ} \mathrm{C}$, in an atmosphere containing $5 \% \mathrm{CO}_{2}$, in Dulbecco's modified Eagle's medium (DMEM; Gibco; Thermo Fisher Scientific, Inc., Waltham, MA, USA) supplemented with $10 \%$ fetal calf serum (HyClone; GE Healthcare Life Sciences, Logan, UT, USA), $100 \mathrm{U} / \mathrm{ml}$ penicillin and $100 \mathrm{mg} / \mathrm{ml}$ streptomycin.

Establishment of tumor models. A total of 30 female Balb/c nude mice (15-18 g, 4 weeks old) were purchased from The Shanghai Laboratory Animal Center, Chinese Academy of Science, and housed in specific pathogen-free conditions that were automatically maintained at a temperature of $23 \pm 2^{\circ} \mathrm{C}$, a relative humidity of $45-65 \%$, and a controlled $12 / 12 \mathrm{~h}$ light/dark cycle. Animals had ad libitum access to food and water. All protocols were approved and supervised by the ethics committee of the First Affiliated Hospital of Nanchang University (Nanchang, China). The mice implanted with the tumor cell line were randomly divided into six groups $(\mathrm{n}=5$ in each group): Control, low-dose naringin $[0.5 \mathrm{mg} / \mathrm{kg}$, intraperitoneal (i.p.)], middle-dose naringin ( $1 \mathrm{mg} / \mathrm{kg}$, i.p.), high-dose naringin $(2 \mathrm{mg} / \mathrm{kg}$, i.p.), positive control (cisplatin, $2 \mathrm{mg} / \mathrm{kg}$, i.p.), and combination of cisplatin and naringin (cisplatin, $2 \mathrm{mg} / \mathrm{kg}$; naringin, $2 \mathrm{mg} / \mathrm{kg}$ ). SKOV3 cells in the logarithmic growth phase $\left(1 \times 10^{7}\right)$ were diluted in $0.2 \mathrm{ml} \mathrm{PBS}$ and injected (i.p) into the Balb/c nude mice. Naringin (purity, $>90 \%$; Sigma-Aldrich; Merck KGaA, Darmstadt, Germany) and/or cisplatin (Sigma-Aldrich; Merck KGaA) were administered for 10 consecutive days, following attainment of a tumor size of $50 \mathrm{~mm}^{3}$. General conditions of the mice were monitored daily and the tumor size was measured every two days. Following 10 days of drug administration, the mice were anesthetized using isoflurane and decapitated thereafter, and the whole tumor was removed. The tumor specimens were fixed in $4 \%$ paraformaldehyde in PBS ( $\mathrm{pH} 7.4$ ) at $4^{\circ} \mathrm{C}$ overnight and then embedded in paraffin for tissue sectioning.

Reverse transcription-polymerase chain reaction (RT-PCR). Total RNA was extracted from the tumors using a TRIzol ${ }^{\circledR}$ kit (Thermo Fisher Scientific, Inc.), according to the manufacturer's instructions. The purity of mRNA was determined using the optical density (OD) at 280/260 $\mathrm{nm}$. Reverse transcription was performed using Random Primer kit (Hexadeoxyribonucleotide mixture; cat. no. 3801; Takara Biotechnology, Co., Ltd., Dalian, China) and Moloney murine leukemia virus reverse transcriptase (Promega Corporation, Madison, WI, USA). The primers were added into a $25-\mu 1$ PCR reaction system, following a protocol of denaturation at $95^{\circ} \mathrm{C}$ for $46 \mathrm{sec}$, annealing at $60^{\circ} \mathrm{C}$ for $45 \mathrm{sec}$, and then elongation at $72^{\circ} \mathrm{C}$ for $60 \mathrm{sec}$ for 36 cycles. The primers were as follows: Cyclin D1, forward AAACTGAAATGGGACTTGG and reverse AGGGTGGATTGGAGATAAA; survivin, forward TTCATCCACTGCCCTACC and reverse GTGCTTTCTATG CTCCTCTAT; c-Myc, forward GGGAGTGGTTCAGGA TTGG and reverse GCATCGTCGTGGCTGTCT; caspase-7, forward GTTGACGCCAAGCCAGAC and reverse AATCCA TGCGGTACAGATAAG; caspase-3, forward CTAATCTGA CGGTCCTCC and reverse TCGCCAAATCTTGCTAAT; Bcl-xL, forward GGGCTGTCTGTCGAATCTG and reverse CTGGAGGCGTAAGGTCAA; Bcl-2, forward ACGTGT AACTTGTAGCGGATAT and reverse GCTGAAAGGTGA
AGAGGC; and GAPDH, forward GCAAGTTCAACGGCA CAG and reverse CGCCAGTAGACTCCACGAC.

Terminal deoxynucleotidyl transferase dUTP nick end labeling (TUNEL) assay. TUNEL staining was performed on $30 \mu \mathrm{m}$ slices using the DeadEnd ${ }^{\mathrm{TM}}$ Colorimetric TUNEL System (Promega Corporation), following the manufacturer's instructions. Following staining, the sections were observed using a FV1000 Olympus Confocal Laser Scanning Microscope (Olympus Corporation, Tokyo, Japan).

Immunohistochemical staining (IHC). Tumor tissues were fixed in $10 \%$ formaldehyde at room temperature for $24 \mathrm{~h}$ and embedded in paraffin. The $3-\mu \mathrm{m}$ sections were continuously sliced. Following dewaxing by xylene, the tissues were dehydrated in 70, 75, 80, 85 and $95 \%$ alcohol. To retrieve the antigen, $3 \%$ hydrogen peroxide was applied at $100^{\circ} \mathrm{C}$. The slices were blocked in 5\% BSA (Hyclone; GE Healthcare Life Sciences, Logan, UT, USA) at $37^{\circ} \mathrm{C}$ for $30 \mathrm{~min}$. Immunostaining of histological sections was performed using monoclonal antibodies against cyclin D1 (dilution, 1:200; cat no. ab134175), c-Myc (dilution, 1:200; cat no. ab32072), survivin (dilution, 1:200; cat no. ab469), caspase-3 (dilution, 1:200; cat no. ab13585), caspase-7 (dilution, 1:200; cat no. ab69540), Bcl-2 (dilution, 1:200; cat no. ab32124) and Bcl-xL (dilution, 1:200; cat no. ab32370; all from Abcam, Cambridge, MA, USA) overnight at $4^{\circ} \mathrm{C}$, followed by a $30 \mathrm{~min}$ incubation with horseradish peroxidase (HRP)-coupled secondary antibodies goat anti-mouse immunoglobulin (Ig)G HRP (dilution, 1:500; cat no. P0447; Dako; Agilent Technologies, Inc., Santa Clara, CA, USA) or goat anti-rabbit IgG HRP (dilution, 1:500, cat no. P0448; Dako; Agilent Technologies, Inc., Santa Clara, CA, USA) and then sections were visualized with diaminobenzidine for 3 min under a light microscope with x200 magnification. PBS was used instead of the primary antibody in the negative control group. The positive staining was analyzed using ImageJ software version 1.48 (National Institutes of Health, Bethesda, MD, USA).

Statistical analysis. Data are presented as the mean \pm standard error of the mean and analyzed by SPSS 19.0 (IBM Corp., Armonk, NY, USA). One-way analysis of variance with Bonferroni correction post-hoc for multiple comparisons was performed. $\mathrm{P}<0.05$ was considered to indicate a statistically significant difference.

\section{Results}

Naringin inhibits ovarian cancer growth. As depicted in Fig. 1A and B, in the first four days of treatment, the mean values of tumor sizes in each group were comparable. By contrast, following treatment for six days, the tumor inhibition by naringin was observable based upon the tumor sizes, particularly in the naringin and cisplatin combination group. Following 10 days of treatment, the tumor size (mean value) in each group was in the following order (largest to smallest): Control, $0.5 \mathrm{mg} / \mathrm{kg}$ naringin, $1 \mathrm{mg} / \mathrm{kg}$ naringin, $2 \mathrm{mg} / \mathrm{kg}$ naringin, positive control and combination (Fig. 1B). The data indicated that naringin inhibits tumor growth in a dose-dependent manner. The tumor weight was 
A
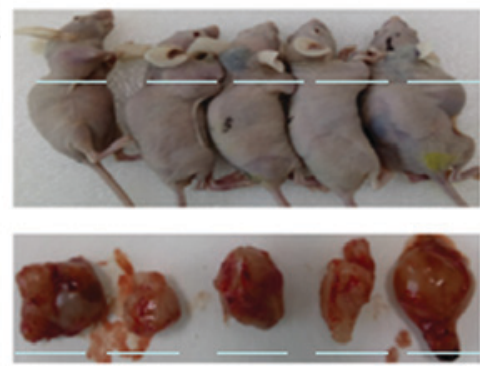

$10 \mathrm{~mm} \quad$ Negative control
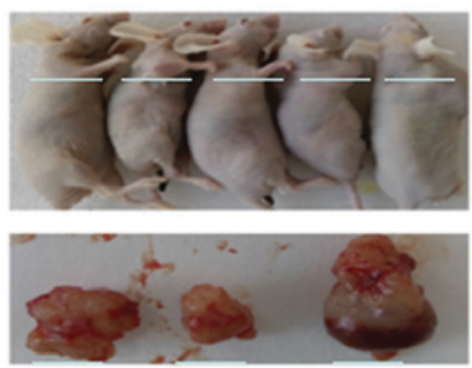

$10 \mathrm{~mm} \quad 2 \mathrm{mg} / \mathrm{kg}$
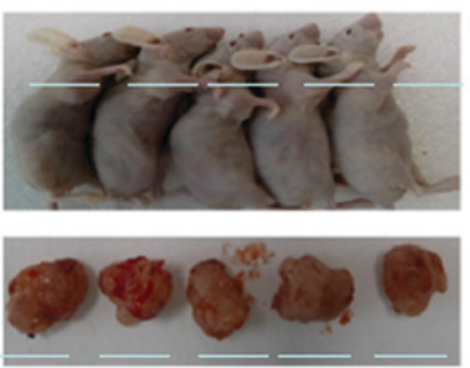

$10 \mathrm{~mm} \quad 0.5 \mathrm{mg} / \mathrm{kg}$
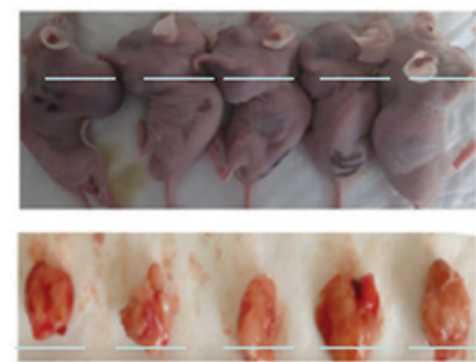

$10 \mathrm{~mm}$ Positive control
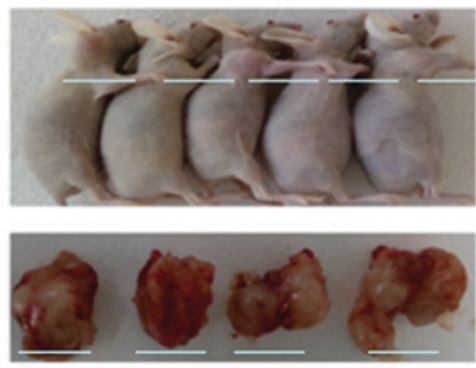

$10 \mathrm{~mm} \quad 1 \mathrm{mg} / \mathrm{kg}$
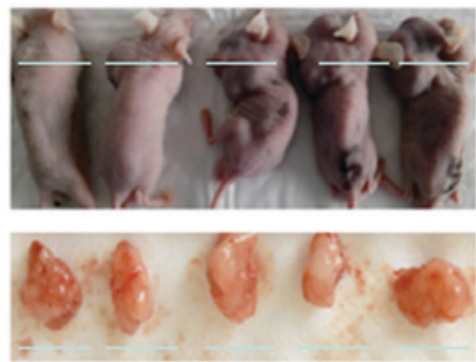

$10 \mathrm{~mm}$ Combination
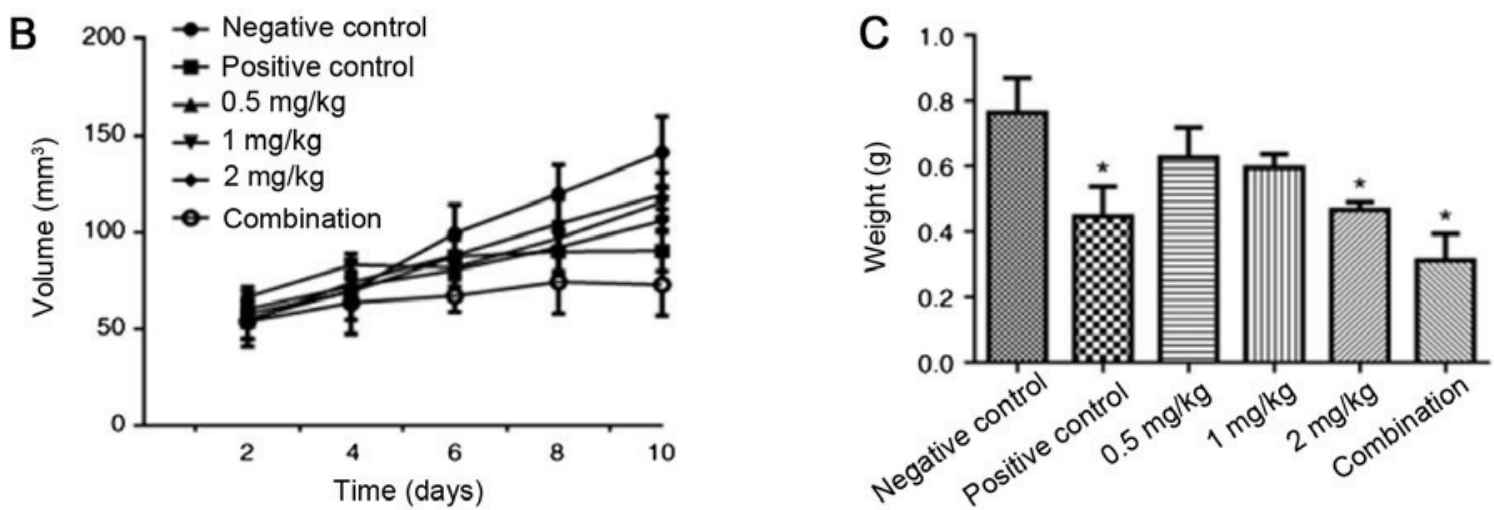

Figure 1. Naringin inhibited ovarian cancer growth. (A) The nude mice and tumors. (B) Volume and (C) weight of the tumors following naringin administration. The data are expressed as the mean \pm standard error of the mean. $\mathrm{n}=5$ in each group. ${ }^{*} \mathrm{P}<0.05$, compared with the negative control.

also measured. As depicted in Fig. 1C, cisplatin, $2 \mathrm{mg} / \mathrm{kg}$ naringin, and the cisplatin and naringin combination significantly reduced the tumor weight, compared with the control $(\mathrm{P}<0.05)$.

Naringin promotes apoptosis in ovarian tumors. Apoptosis was detected in the tumor cells. As depicted in Fig. 2, naringin triggered apoptosis in ovarian tumors in a dose-dependent manner in the range $0.5-2 \mathrm{mg} / \mathrm{kg}$. The cisplatin, $2 \mathrm{mg} / \mathrm{kg}$ naringin, and cisplatin and naringin combination groups notably promoted apoptosis.

Naringin regulates apoptosis-associated gene expression. Apoptosis-associated gene expression was also detected. As depicted in Fig. 3, naringin increased the expression of caspase-7 and caspase-3 protein (Fig. 3A) and mRNA (Fig. 3B) in a dose-dependent manner. In particular, the cisplatin, $2 \mathrm{mg} / \mathrm{kg}$ naringin, and cisplatin and naringin combination groups notably promoted the expression of caspase- 7 and caspase-3, compared with the control $(\mathrm{P}<0.05)$.

The expression of $\mathrm{Bcl}-2$ and $\mathrm{Bcl}-\mathrm{xL}$ was also evaluated via IHC (Fig. 4A) and RT-PCR (Fig. 4B). Naringin reduced the expression of $\mathrm{Bcl}-2$ and $\mathrm{Bcl}-\mathrm{xL}$ protein and mRNA in a dose-dependent manner. In particular, the cisplatin, $2 \mathrm{mg} / \mathrm{kg}$ naringin, and cisplatin and naringin combination groups significantly reduced the expression of Bcl-2 and Bcl-xL, compared with the control $(\mathrm{P}<0.05)$.

Naringin reduces cell growth-associated gene expression. Cyclin D1, c-Myc and survivin were detected in each group. As depicted in Fig. 5, naringin reduced the expression of cyclin D1, c-Myc and survivin protein (Fig. 5A) and mRNA (Fig. 5B) in a dose-dependent manner. In particular, the cisplatin, $2 \mathrm{mg} / \mathrm{kg}$ naringin and cisplatin and naringin combination groups significantly reduced cyclin D1, c-Myc and survivin, compared with the control $(\mathrm{P}<0.05)$.

\section{Discussion}

In the present study, nude mouse tumor xenograft models were produced and administered naringin. The data demonstrated that the tumor volume and weight were reduced gradually with the increased dose of naringin, and that naringin has an antitumor effect in vivo. 


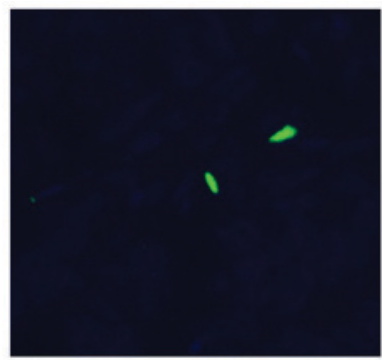

Negative control

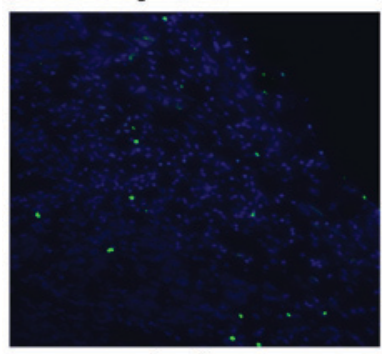

$2 \mathrm{mg} / \mathrm{kg}$

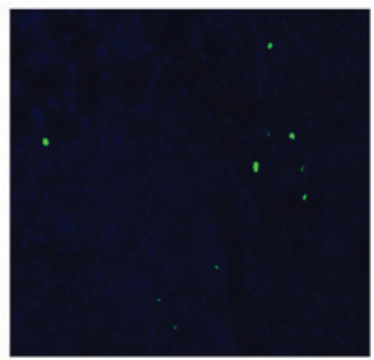

$0.5 \mathrm{mg} / \mathrm{kg}$

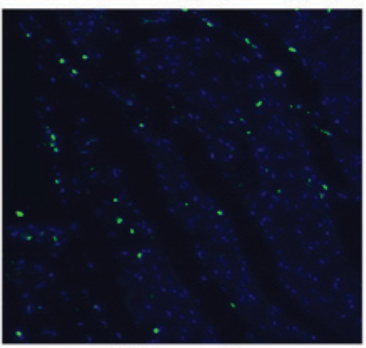

Positive control

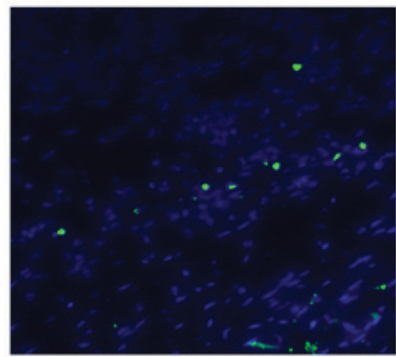

$1 \mathrm{mg} / \mathrm{kg}$

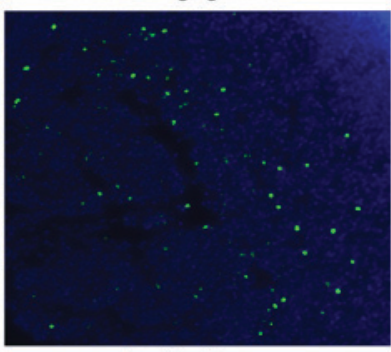

Combination

Figure 2. Naringin promoted apoptosis in the ovarian tumors. The blue staining indicated the nucleus with green staining indicating apoptosis. The green cells were pronounced in the model group.

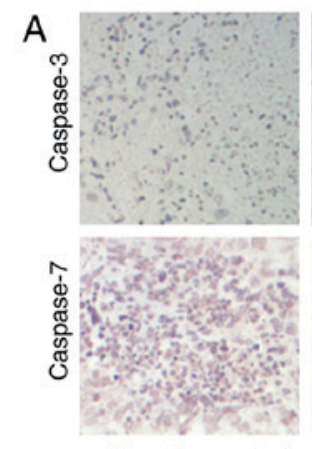

Negative control

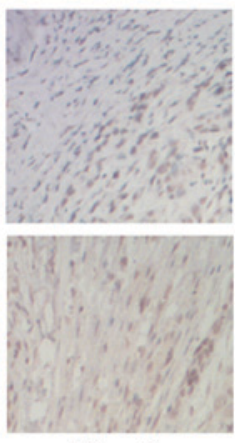

$0.5 \mathrm{mg} / \mathrm{kg}$

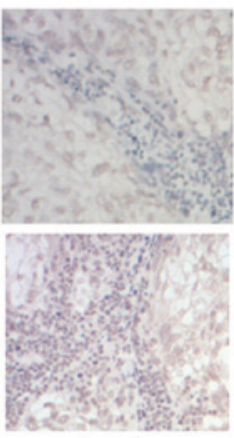

$1 \mathrm{mg} / \mathrm{kg}$

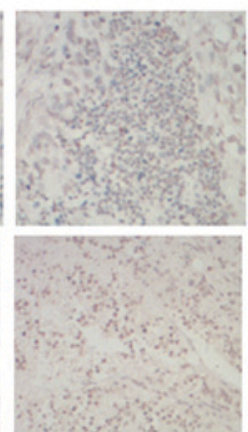

$2 \mathrm{mg} / \mathrm{kg}$

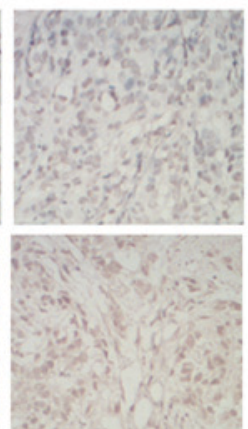

Positive control

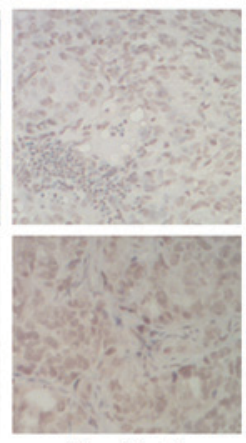

Combination

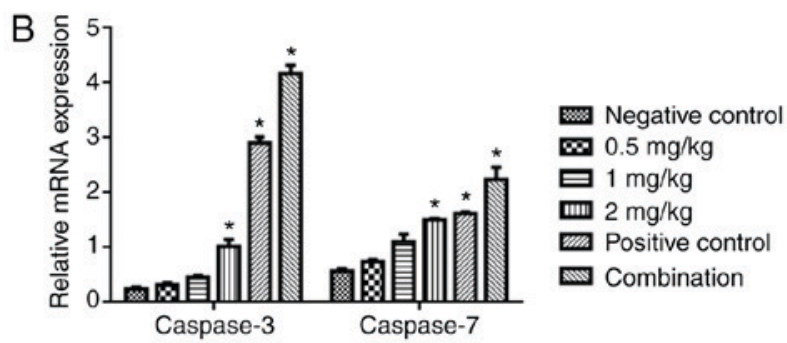

Figure 3. Naringin increased the expression of caspase-7 and caspase-3. (A) Protein expression as detected by immunohistochemistry. (B) mRNA expression as detected by reverse transcription-polymerase chain reaction. The data are expressed as the mean \pm standard error of the mean. $n=5$ in each group. " $\mathrm{P}<0.05$, compared with the negative control.

Caspases belong to the aspartic acid specific cysteine protease family (17). Caspase-3 and caspase-7 serve important roles in the process of apoptosis (18). Caspase-3 is a regulator of cell death (18). When caspase-3 is inhibited, apoptosis is prohibited, which contributes to tumorigenesis (19). A previous study demonstrated that caspase- 3 and caspase-7 have synergistic effects in promoting apoptosis (20). The results also demonstrated that the expression of caspase- 3 and caspase-7 was upregulated significantly with an increased dose of naringin. The results indicated that naringin has the ability to induce apoptosis via promoting the expression of caspase- 3 and caspase-7. Bcl-2 can inhibit the apoptosis of tumor cells (21) and Bcl-xL prohibits apoptosis in the absence of a cell growth factor (21). Takehara et al (22) revealed that the expression level of Bcl-xL in hepatocellular carcinoma tissues was significantly higher, compared with paracancerous tissue, which could inhibit apoptosis during serum starvation and p53 activation. The results demonstrated that naringin reduced the expression of $\mathrm{Bcl}-2$ and $\mathrm{Bcl}-\mathrm{xL}$, which promoted apoptosis. The data further indicated that naringin has an antitumor effect via the promotion of apoptosis. 
A

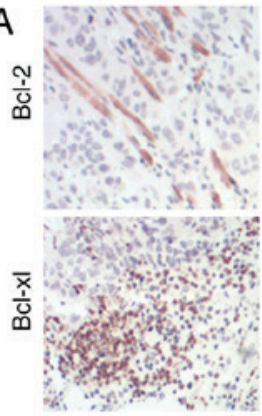

Negative control

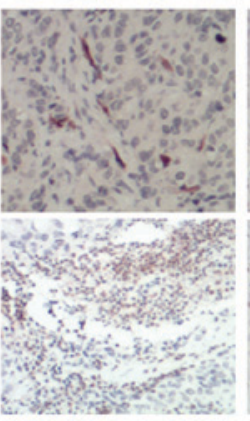

$0.5 \mathrm{mg} / \mathrm{kg}$

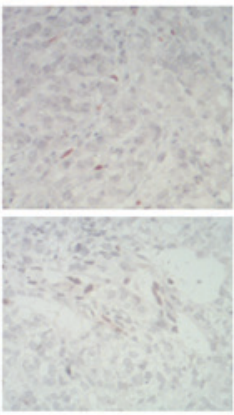

$1 \mathrm{mg} / \mathrm{kg}$

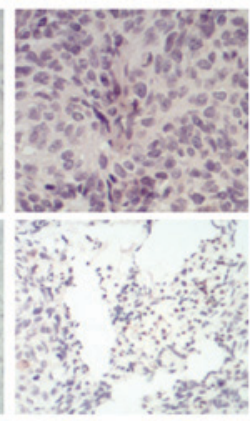

$2 \mathrm{mg} / \mathrm{kg}$

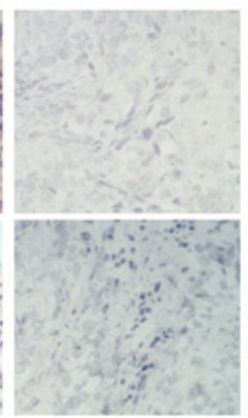

Positive control

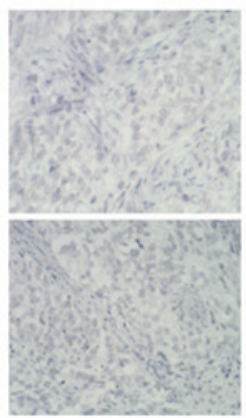

Combination

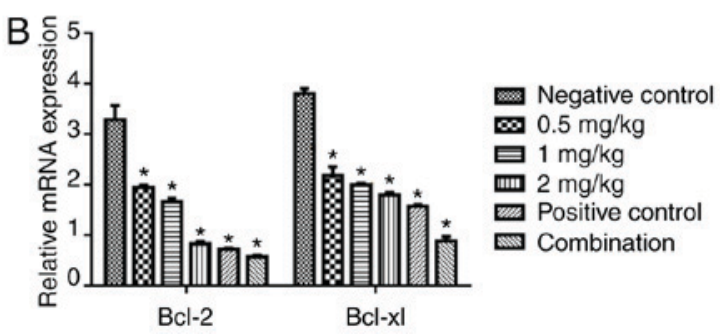

Figure 4. Naringin reduced the expression of Bcl-2 and Bcl-xL. (A) Protein expression as detected by immunohistochemistry. (B) mRNA expression as detected by reverse transcription-polymerase chain reaction. The data are expressed as the mean \pm standard error of the mean. $\mathrm{n}=5$ in each group. "P<0.05, compared with the negative control. Bcl-xL, B-cell lymphoma-extra large.

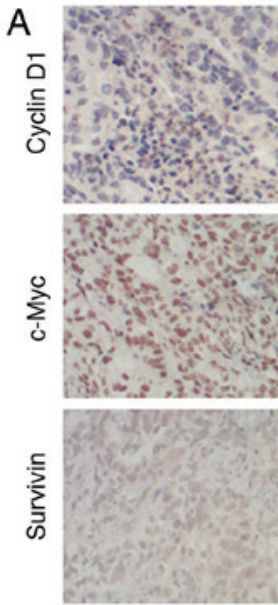

Negative control

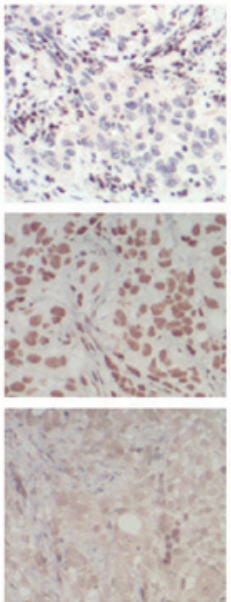

$0.5 \mathrm{mg} / \mathrm{kg}$
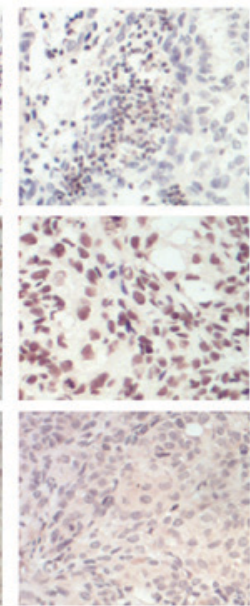

$1 \mathrm{mg} / \mathrm{kg}$

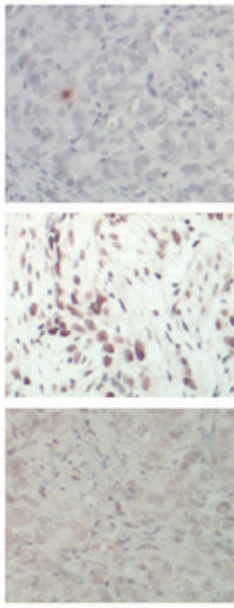

$2 \mathrm{mg} / \mathrm{kg}$

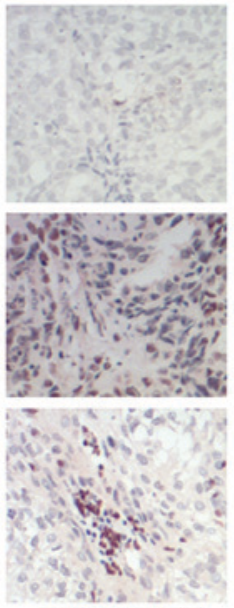

Positive control
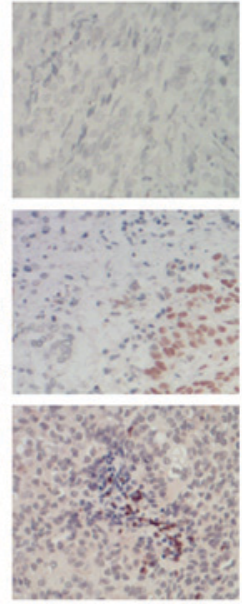

Combination

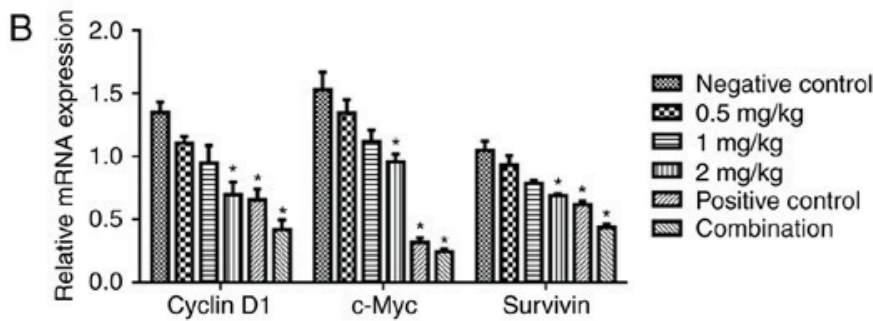

Figure 5. Naringin reduced the expression of cyclin D1, c-Myc and survivin. (A) Protein expression as detected by immunohistochemistry. (B) mRNA expression as detected by reverse transcription-polymerase chain reaction. The data are expressed as the mean \pm standard error of the mean. $\mathrm{n}=5$ in each group. ${ }^{*} \mathrm{P}<0.05$, compared with the negative control.

Cyclin D1 belongs to the group of cell cycle regulating proteins, can be expressed continuously under mitogen stimulation, which can then promote cell proliferation, and participate in tumorigenesis (23). Cyclin D1 is highly expressed in tumor cells; it is not only associated with the occurrence and development of tumors, but also with tumor prognosis, metastasis and tumor recurrence following radiotherapy (24). c-Myc affects the processes of cell growth, differentiation and apoptosis, and the cell cycle, and the abnormal expression of these molecules frequently occurs in the early phase of carcinogenesis; in addition, it is closely associated with tumor proliferation and the initiation of cancer (25). c-Myc 
has dual effects; not only does it promote cell apoptosis, but it also stimulates cell proliferation (26). As a nuclear protein-regulating gene, c-Myc serves an important role in regulating tumor-associated gene expression and modulating cell invasion, growth and metastasis (27); however, overexpression of c-Myc alone cannot cause the malignant change in tissues $(28,29)$. The survivin gene is a novel inhibitor of apoptosis (30), which participates in regulating cell growth and proliferation (31). The results demonstrated that with an increase in the naringin concentration, the protein expression of cyclin D1, c-Myc and survivin was reduced significantly. These results indicate that naringin can induce apoptosis in tumor cells.

In conclusion, the data demonstrated that naringin inhibited ovarian tumor growth in vivo. Its mechanisms may be associated with caspase-7, caspase-3, Bcl-2 and Bcl-xL-mediated apoptosis. Furthermore, naringin also reduced the expression of cyclin D1, c-Myc and survivin. Nevertheless, the clinical application of naringin in the treatment of ovarian cancer warrants further study.

\section{Acknowledgements}

The present study was supported by The Science and Technology Support Plan from Jiangxi, China (grant no. 20152ACG70022).

\section{References}

1. Viau M, Renaud MC, Gregoire J, Sebastianelli A and Plante M Paraneoplastic syndromes associated with gynecological cancers: A systematic review. Gynecol Oncol 146: 661-671, 2017.

2. Banach P, Suchy W, Dereziński P, Matysiak J, Kokot ZJ and Nowak-Markwitz E: Mass spectrometry as a tool for biomarkers searching in gynecological oncology. Biomed Pharmacother 92 836-842, 2017.

3. Jelovac D and Armstrong DK: Recent progress in the diagnosis and treatment of ovarian cancer. CA Cancer J Clin 61: 183-203, 2011.

4. Armstrong DK, Bundy B, Wenzel L, Huang HQ, Baergen R, Lele S, Copeland LJ, Walker JL and Burger RA; Gynecologic Oncology Group: Intraperitoneal cisplatin and paclitaxel in ovarian cancer. N Engl J Med 354: 34-43, 2006.

5. Zhou YF: High intensity focused ultrasound in clinical tumor ablation. World J Clin Oncol 2: 8-27, 2011.

6. To SKY, Mak ASC, Eva Fung YM, Che CM, Li SS, Deng W, $\mathrm{Ru}$ B, Zhang J and Wong AST: $\beta$-catenin downregulates Dicer to promote ovarian cancer metastasis. Oncogene 36: 5927-5938, 2017.

7. Mihanfar A, Fattahi A and Nejabati HR: MicroRNA-mediated drug resistance in ovarian cancer. J Cell Physiol, Jun 19, 2017 (Epub ahead of print)

8. Kuo YT, Chang TT, Muo CH, Wu MY, Sun MF, Yeh CC and Yen HR: Use of complementary traditional chinese medicines by adult cancer patients in Taiwan: A nationwide population-based study. Integr Cancer Ther: June 1, 2017 (Epub ahead of print).

9. Singh N, Bansal Y, Bhandari R, Marwaha L, Singh R, Chopra K and Kuhad A: Naringin reverses neurobehavioral and biochemical alterations in intracerebroventricular collagenase-induced intracerebral hemorrhage in rats. Pharmacology 100: 172-187, 2017.

10. Chen R, Qi QL, Wang MT and Li QY: Therapeutic potential of naringin: An overview. Pharm Biol 54: 3203-3210, 2016.

11. Jeon SM, Bok SH, Jang MK, Kim YH, Nam KT, Jeong TS, Park YB and Choi MS: Comparison of antioxidant effects of naringin and probucol in cholesterol-fed rabbits. Clin Chim Acta 317: 181-190, 2002.

12. Jagetia GC and Reddy TK: Modulation of radiation-induced alteration in the antioxidant status of mice by naringin. Life Sci 77 : 780-794, 2005.
13. Rajadurai M and Stanely Mainzen Prince P: Preventive effect of naringin on lipid peroxides and antioxidants in isoproterenol-induced cardiotoxicity in Wistar rats: Biochemical and histopathological evidences. Toxicology 228: 259-268, 2006.

14. Li W, Wang C, Peng J, Liang J, Jin Y, Liu Q, Meng Q, Liu K and Sun $\mathrm{H}$ : Naringin inhibits TNF- $\alpha$ induced oxidative stress and inflammatory response in HUVECs via Nox4/NF- $\kappa$ B and PI3K/Akt pathways. Curr Pharm Biotechnol 15: 1173-1182, 2014.

15. Ramalingayya GV, Nampoothiri M, Nayak PG, Kishore A, Shenoy RR, Mallikarjuna Rao C and Nandakumar K: Naringin and rutin alleviates episodic memory deficits in two differentially challenged object recognition tasks. Pharmacogn Mag 12 (Suppl 1): S63-S70, 2016.

16. Cao X, Lin W, Liang C, Zhang D, Yang F, Zhang Y, Zhang X, Feng $J$ and Chen C: Naringin rescued the TNF- $\alpha$-induced inhibition of osteogenesis of bone marrow-derived mesenchymal stem cells by depressing the activation of NF- $\mathrm{BB}$ signaling pathway. Immunol Res 62: 357-367, 2015.

17. Chang HY and Yang X: Proteases for cell suicide: Functions and regulation of caspases. Microbiol Mol Biol Rev 64: 821-846, 2000.

18. Zhu G, Wang X, Wu S and Li Q: Involvement of activation of PI3K/Akt pathway in the protective effects of puerarin against MPP+-induced human neuroblastoma SH-SY5Y cell death. Neurochem Int 60: 400-408, 2012.

19. Linder M and Tschernig T: Vasculogenic mimicry: Possible role of effector caspase-3, caspase-6 and caspase-7. Ann Anat 204: 114-117, 2016.

20. Médoc M, Dhilly M, Matesic L, Toutain J, Krause-Heuer AM, Delamare J, Fraser BH, Touzani O, Barré L, Greguric I and Sobrio F: In vivo evaluation of radiofluorinated caspase-3/7 inhibitors as radiotracers for apoptosis imaging and comparison with [18F]ML-10 in a stroke model in the rat. Mol Imaging Biol 18: 117-126, 2016.

21. Zolota V, Gerokosta A, Melachrinou M, Kominea A, Aletra C and Scopa CD: Microvessel density, proliferating activity, p53 and bcl-2 expression in in situ ductal carcinoma of the breast. Anticancer Res 19: 3269-3274, 1999.

22. Takehara T, Liu X, Fujimoto J, Friedman SL and Takahashi H: Expression and role of Bcl-xL in human hepatocellular carcinomas. Hepatology 34: 55-61, 2001.

23. Li Z, Cui J, Yu Q, Wu X, Pan A and Li L: Evaluation of CCND1 amplification and CyclinD1 expression: Diffuse and strong staining of CyclinD1 could have same predictive roles as CCND1 amplification in ER positive breast cancers. Am J Transl Res 8: 142-153, 2016.

24. Yamamoto K, Lee BJ, Li C, Dubois RL, Hobeika E, Bhagat G and Zha S: Early B-cell-specific inactivation of ATM synergizes with ectopic CyclinD1 expression to promote pre-germinal center B-cell lymphomas in mice. Leukemia 29: 1414-1424, 2015.

25. Kandela I, Jin HY and Owen K; Reproducibility Project: Cancer biology: Registered report: BET bromodomain inhibition as a therapeutic strategy to target c-Myc. Elife 4: e07072, 2015.

26. Lin CY, Lovén J, Rahl PB, Paranal RM, Burge CB, Bradner JE, Lee TI and Young RA: Transcriptional amplification in tumor cells with elevated c-Myc. Cell 151: 56-67, 2012.

27. Zhang E, Li W, Yin D, De W, Zhu L, Sun S and Han L: c-Myc-regulated long non-coding RNA H19 indicates a poor prognosis and affects cell proliferation in non-small-cell lung cancer. Tumour Biol 37: 4007-4015, 2016.

28. Wu DW, Hsu NY, Wang YC, Lee MC, Cheng YW, Chen CY and Lee H: c-Myc suppresses microRNA-29b to promote tumor aggressiveness and poor outcomes in non-small cell lung cancer by targeting FHIT. Oncogene 34: 2072-2082, 2015.

29. Xia B, Tian C, Guo S, Zhang L, Zhao D, Qu F, Zhao W, Wang Y, Wu X, Da W, et al: c-Myc plays part in drug resistance mediated by bone marrow stromal cells in acute myeloid leukemia. Leuk Res 39: 92-99, 2015

30. Kato J, Kuwabara Y, Mitani M, Shinoda N, Sato A, Toyama T, Mitsui A, Nishiwaki T, Moriyama S, Kudo J and Fujii Y: Expression of survivin in esophageal cancer: Correlation with the prognosis and response to chemotherapy. Int J Cancer 95: 92-95, 2001.

31. Mitrović Z, Ilić I, Aurer I, Kinda SB, Radman I, Dotlić S, Ajduković R and Labar B: Prognostic significance of survivin and caspase-3 immunohistochemical expression in patients with diffuse large B-cell lymphoma treated with rituximab and CHOP. Pathol Oncol Res 17: 243-247, 2011.

This work is licensed under a Creative Commons Attribution-NonCommercial-NoDerivatives 4.0 International (CC BY-NC-ND 4.0) License. 